\title{
Falla hepática fulminante por virus hepatitis B en paciente coinfectado por VIH: un desafío terapéutico. Caso clínico
}

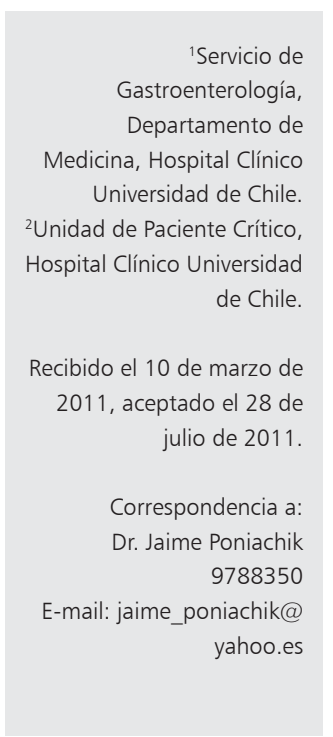

\author{
SUSANA SAGREDO ${ }^{1}$, CARLA MANCILLA ${ }^{2}$, \\ NIVIA ESTUARDO ${ }^{2}$, JAIME PONIACHIK ${ }^{1}$
}

The human immunodeficiency virus (HIV) and hepatitis B virus (HBV) coinfection is a common problem in the world, with an estimated prevalence of up to $8 \%$. We report a 27-year-old man admitted to the intensive care unit with an acute liver failure by HBV. During hospital stay, a co-infection with HIV virus was detected. Treatment with early antiviral therapy was started with emtricitabine, tenofovir and raltegravir, to cover both $\mathrm{HBV}$ and HIV. Despite therapy, the patient died two weeks after admission.

(Rev Med Chile 2011; 139: 1336-1339).

Key words: Liver failure, acute: Hepatitis B virus; HIV.

L os virus de inmunodeficiencia humana (VIH) y virus hepatitis B (VHB) comparten las vías de transmisión, por lo que es esperable la coinfección con ambos, estimándose 4 millones de coinfectados en el mundo ${ }^{1}$. En pacientes VIH positivo la infección crónica por VHB es 10 veces más frecuente que en la población general, llegando al $8 \%{ }^{3,4}$.

En Chile se ha estudiado la prevalencia de ambos virus, estimandose la coinfección en $48 \%$ en hombres y $23 \%$ en mujeres, sin embargo, estas cifras incluyen también a pacientes con anticore total positivo aislado, por lo que la coinfección puede estar sobreestimada ${ }^{2}$.

La enfermedad hepática por VHB en coinfectados cursa con mayores niveles de ADN circulante, pero la actividad necroinflamatoria es menor, probablemente porque ésta requiere de un sistema inmune competente. El daño histológico sin embargo, progresa más rápido, llegando precozmente a cirrosis y con mayor mortalidad, la que se estima 17 veces mayor que en no coinfectados. Por otra parte, el riesgo de cronicidad es mayor (estimándose en 23\%) y la tasa de seroconversión espontánea para antígeno de superficie (HBsAg) y antígeno e (HBAge) menor ${ }^{3,4}$. A la inversa la infección crónica por VHB parece no afectar la evolución de la infección por VIH, pero sí puede complicar el uso de terapia antirretroviral (TARV) por mayor hepatotoxicidad 5 .

Lamentablemente poco se sabe de la historia natural de la hepatitis fulminante (HF) por VHB en coinfectados, y menos aun del manejo de estos pacientes, existiendo pocos casos reportados en la literatura ${ }^{6,7}$. Por ello nos parece relevante presentar el caso de un paciente VIH positivo que desarrolló HF por VHB.

\section{Caso clínico}

Hombre de 27 años sin antecedentes mórbidos, consultó en Antofagasta por compromiso del estado general y fiebre de 5 días, con posterior aparición de ictericia. Se hospitalizó con bilirrubina total de $13 \mathrm{mg} / \mathrm{dl}$, aminotransferasa oxalacética de $1.977 \mathrm{mU} / \mathrm{ml}$ y pirúvica de $5.975 \mathrm{mU} / \mathrm{ml}$, fosfata- 
Tabla 1. Evolución de los exámenes de laboratorio desde el ingreso al Hospital Clínico de la Universidad de Chile

\begin{tabular}{|lllllll|}
\hline Exámenes & Día 1 & Día 3 & Día 5 & Día 7 & Día 10 & Día 13 \\
\hline Bili total & 20 & 23 & 17 & 23 & 23 & 17 \\
\hline FA/GGT & $202 / 66$ & $191 / 57$ & $113 / 51$ & $98 / 53$ & $89 / 42$ & $71 / 27$ \\
\hline GOT/GPT & $284 / 1.539$ & $117 / 880$ & $65 / 391$ & $60 / 249$ & $74 / 138$ & $66 / 79$ \\
\hline TP \% & $37 \%$ & $24 \%$ & $45 \%$ & $37 \%$ & $24 \%$ & $25 \%$ \\
\hline Creatinina & 0,4 & 0,5 & 0,4 & 0,8 & 0,3 & 0,8 \\
\hline Leucocitos/ml & 9.800 & 9.300 & 4.600 & 6.300 & 5.800 & 6.500 \\
\hline Plaquetas/ml & 304.000 & 309.000 & 71.000 & 48.000 & 19.000 & 26.000 \\
\hline Albúmina & 3,2 & - & 3,0 & 2,7 & 2,0 & 1,9 \\
\hline
\end{tabular}

Bili total: bilirrubina total (mg/dl), GOT: aminotransferasa oxalacética, GPT: aminotransferasa pirúvica, GGT: gamaglutamil tranferasa, FA: fosfatasas alcalinas, TP \%: porcentaje del tiempo de protrombina normal. Creatinina en mg/dl.

sas alcalinas de $157 \mathrm{U} / \mathrm{L}$, y tiempo de protrombina $15 \%$. Del panel viral resultó positivo un HBsAg. Evolucionó con compromiso de conciencia hasta Glasgow 8, con tomografía computada (TC) de cerebro normal, por lo que fue derivado a nuestro centro.

Fue recibido en la Unidad de Cuidados Intensivos con Glasgow 5 sospechándose broncoaspiración. Se conectó a ventilación mecánica, se iniciaron antibióticos y $\mathrm{N}$-acetil cisteína.

La TC de tórax reveló neumonía, y la de cerebro edema cerebral leve. La ecotomografía abdominal muestró hígado normal y ascitis leve.

$\mathrm{Al}$ suspender la sedación persistía en coma y con pupilas arreflécticas.

La evolución de las pruebas de laboratorio se muestra en la Tabla 1.

Dentro del estudio etiológico presenta serología para virus hepatitis $\mathrm{C}$ y A y estudio de autoinmunidad (anticuerpos y recuento de inmunoglobulinas) negativos. Se repitió el estudio del VHB destacando aparición de anticuerpos contra el HBsAg (antiHBs) y negativización del HBsAg, con anticore positivos, IgM y total.

Se realizó ELISA para VIH, que resultó positivo, y recuento de CD4 de 634 células/ul.

La carga viral (CV) del VHB fue de 140 copias/ $\mathrm{ml}$, y la del VIH 16.900 copias RNA/ml.

Se inició TARV, al $2^{\circ}$ día, con emtricitabina, tenofovir y raltegravir, para cubrir ambos virus.

Se planteó la necesidad de trasplante hepático (THO), pero la infección respiratoria no permite activarlo como urgencia.
Se realizan sesiones de Molecular Adsorbent Recirculation System, completando un total de 31 horas.

Seis días después del ingreso presentó nuevo deterioro respiratorio, sospechándose neumonía intrahospitalaria que se trató.

Evolucionó con falla orgánica múltiple y sepsis de foco pulmonar (con Enterococcus faecalis en lavado broncqueoalveolar). Se agregó finalmente oligoanuria, iniciándose hemodiafiltración venovenosa continua.

A 12 días del ingreso presentó midriaisis arrefléctica y TC mostró gran edema cerebral con compresión de tronco encefálico. Falleció 2 semanas posterior al ingreso.

\section{Discusión}

La HF por VHB ocurre en aproximadamente $0,1 \%$ de los que se infectan por este virus, pudiendo ocasionalmente resolverse en forma espontánea, con tratamiento de sostén, o bien requerir THO y pudiendo fallecer aquellos que no alcanzan a recibirlo.

Se sabe que el sistema inmune es fundamental en la injuria hepática gatillada por este virus, de modo que mientras mayor es la respuesta del hospedero, mayor la probabilidad de desarrollar HF. Por lo mismo sería esperable que en estados de inmunodepresión como es el tener VIH avanzado, el desarrollo de HF sea infrecuente. En nuestro paciente destaca que si bien estaba co- 
infectado fue capaz de desarrollar una respuesta inmune tal que se manifestó por insuficiencia hepática aguda. Esto se explica porque no se encontraba tan inmunodeprimido, como lo refleja su recuento de CD4. Podríamos hipotetizar que si hubiera estado más inmunodeprimido no habría desarrollado una HF, sino una infección crónica por VHB.

Hasta donde sabemos existen sólo unos pocos casos publicados en la literatura de falla hepática fulminante (FHF) por VHB en pacientes coinfectados, con desenlace fatal en uno de ellos ${ }^{6}$ y con sobrevida post THO precoz en otros ${ }^{7}$.

Por lo mismo y a diferencia de lo que ocurre en pacientes con coinfección crónica, no existen recomendaciones para este grupo de pacientes, quedando la decisión de iniciar tratamiento anti VHB a criterio clínico. Así en relación al inicio de la terapia hay diversas posturas. Para algunos si el VHB está siendo eliminado, como lo suponía la presencia de antiHBsAg y la desaparición del HBsAg en nuestro paciente, no se justificaría tratarlo. Otros plantean tratar el VHB, considerando la gravedad del cuadro gatillado por él, pero no el VIH cuando el recuento de CD4 es alto. Para otros en cambio el tratamiento debiera ser para ambos virus; así las últimas guías americanas de VIH recomiendan tratar ambos cuando existe coinfección. En relación a la TARV en cambio, sí existen recomendaciones tanto para el inicio de ésta, en todo VIH coinfectado con VHB o VHC, como en relación a los medicamentos a utilizar, recomendándose incluir lamivudina o emtricitabina más tenofovir, pues éstos tienen actividad contra ambos virus ${ }^{3,4}$.

En casos de hepatitis aguda por VHB en pacientes no coinfectados no se recomienda iniciar terapia para el VHB, puesto que ya hay una respuesta inmune intentando eliminar el virus, $y$ lo que se preconiza es observación y control serológico. En HF o grave en cambio no existe tanta claridad y algunos autores recomiendan utilizar antivirales en hepatitis aguda severa para disminuir el riesgo de FHF y la necesidad de trasplante ${ }^{8}$. No sabemos si la indicación de tratar uno o ambos virus pudiera ser distinta en la hepatitis aguda grave respecto de la HF. Podríamos hipotetizar que en el primer caso y ante la presencia de algún grado de reserva hepática fuera mejor no tratar el VIH considerando la posibilidad de agravamiento con aumento de la necrosis y progresión a HF si el paciente desarrolla un síndrome de reconstitución inmune al recuperar los CD4. Por otra parte, cuando ya existe FHF, por ende nula reserva hepática, la única alternativa es el trasplante y es poco probable que la TARV empeore aún más la condición hepática.

Con respecto al trasplante, éste se acepta en pacientes con cirrosis e infección por VIH, siempre que no estén muy inmunodeprimidos ${ }^{3}$, con sobrevida comparable a los no VIH, de $92 \%$ al año y $81 \%$ a los 2 años ${ }^{7}$. Es así que en la actualidad la infección por VIH pasó de ser una contraindicación para el THO a estar aceptada en estos casos, independiente de la causa que lo motiva, siempre y cuando el recuento de CD4 sea mayor a 200 células/ml o mayor a 100 si su porcentaje es mayor a $20 \%$. Se requiere además CV de VIH menor a 200 copias/ml o tener opciones válidas de TARV en el postrasplante y no haber tenido enfermedades oportunistas definitorias de SIDA (excepto candidiasis esofágica y tuberculosis $)^{9}$. Dada la baja frecuencia de HF por VHB en infectados por VIH no existen recomendaciones respecto al THO en ellos, pero creemos que lo anteriormente descrito para cirróticos coinfectados es extrapolable a este escenario, asumiendo la mayor morbi-mortalidad que conlleva el tener una FHF. En casos de insuficiencia hepática aguda existe un solo caso reportado de THO en un paciente VIH positivo ${ }^{7}$, con evolución favorable post trasplante. Creemos que la indicación de THO en estos casos pudiera asemejarse a las recomendaciones para cirróticos coinfectados, pero dada la poca experiencia en trasplantar a estos enfermos, es una indicación que debiera discutirse caso a caso.

En nuestro paciente la disminución de la CV deseable previo al THO fue el argumento utilizado para tratarlo, considerando que su única opción era el THO urgente y su alta CV inicial. Además si bien cumplía criterios para THO, no fue posible plantearlo por la infección descontrolada que presentaba.

No existen guías respecto del manejo de pacientes VIH positivos que desarrollan HF por VHB, y en la literatura se encuentran sólo reportes de casos. Es por esto que creemos importante difundir casos como éste, que de seguro se repetirán en el futuro. Pensamos que es también fundamental diseñar estudios multicéntricos, considerando la baja frecuencia en que la coinfección se manifiesta como HF. 


\section{Referencias}

1. Alter MJ. Epidemiology of viral hepatitis and HIV coinfection. J Hepatol 2006; 44 (1 Suppl): S6-S9.

2. Pérez C, Cerón I, Fuentes G, Zañartu C, Balcells ME, Ajenjo C, et al. Coinfecciones por virus hepatitis B, virus hepatitis C, Treponema pallidum y Toxoplasma gondii en la cohorte de pacientes VIH positivos en control en la Pontificia Universidad Católica de Chile. Rev Med Chile 2009; 137: 641-8.

3. Scientific Committee on AIDS and STI (SCAS), Centre for Health Protection, Department of Health. Recommendation on the Management of Human Immunodeficiency Virus and Hepatitis B Coinfection. October 2008.

4. Chloe L. Thio. Hepatitis B and Human Immunodeficiency Virus Coinfection. Hepatology 2009; 49 (5 Suppl): S138-45.

5. Konopnicki D, Mocroft A, de Wit S, Antunes F, Ledergerber B, Katlama C, et al. Hepatitis B and HIV: prevalence,
AIDS progression, response to highly active antiretroviral therapy and increased mortality in the EuroSIDA cohort, AIDS 2005; 19: 593-601.

6. Bagaglio S, Albarello L, Biswas P, Uberti-Foppa C, Fortis C , Morsica G. Virological pattern of hepatitis B infection in an HIV-positive man with fatal fulminant hepatitis B: a case report. Journal of Medical Case Reports 2009; 3: 110.

7. Neff G, Bonham A, Tzakis A, Ragni M, Jayaweera D, Schiff R, et al. Orthotopic Liver Transplantation in Patients With Human Immunodeficiency Virus and End-Stage Liver Disease. Liver Transplantation 2003; 9 (3): 239-47.

8. Lisotti A, Azzaroli F, Buonfiglioli F, Montagnani M, Alessandrelli F, Mazzella G. Lamivudine treatment for severe acute HBV hepatitis. Int J Med Sci 2008; 5: 309-12.

9. Miró JM, Montejo M, Rufí G, Bárcena M, Vargas V, Rimola A, et al. Trasplante hepático en pacientes con infección por el VIH: una realidad en el año 2004. Enferm Infecc Microbiol Clin 2004; 22 (9): 529-38. 